\title{
Late presentation of Ellis van Creveld Syndrome with Common atrium anomaly: A case report in a Nepalese Adult
}

\author{
Anish Hirachan, ${ }^{1 *}$ Bishal K.C, ${ }^{1}$ Arun Maskey, ${ }^{2}$ Madhu Roka, ${ }^{2}$ Gopi Prasad Hirachan ${ }^{3}$ \\ ${ }^{1}$ Department of Cardiology, NAMS, Kathmandu, Nepal, \\ ${ }^{2}$ Department of Cardiology, Sahid Gangalal National Heart Centre, Kathmandu, Nepal \\ ${ }^{3}$ Department of Cardiology, Gandaki Medical College, Pokhara, Nepal
}

\section{DOI Name}

http://dx.doi.org/10.3126/jaim.v7i1.19580

\section{Keywords}

Ellis van Creveld syndrome, narrow thorax,

chondrodystrophy

\section{Citation}

Anish Hirachan, Bishal K.C, Arun Maskey, Madhu Roka, Gopi Prasad Hirachan. Late presentation of Ellis van Creveld Syndrome with Common atrium anomaly: A case report in a Nepalese Adult. Journal of Advances in Internal Medicine 2017;06(01):2629.

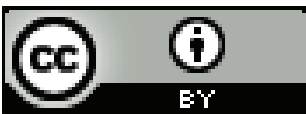

This work is licensed under a Creative Commons

\section{ABSTRACT}

Ellis Van Creveld syndrome (EVC) is a rare genetic disorder having autosomal recessive inheritance characterized by chondrodystrophy, polydactyly, ectodermal dysplasia, and various cardiac anomalies. Acromelic shortening of upper and lower limbs, genu valgum, deformed teeth, short ribs and narrow thorax and other systemic anomalies complete the picture of this syndrome. The patients with the syndrome rarely survive into adulthood. Here, we report a 30 year old male with EVC presenting for the first time in middle age with Common atrium anomaly .

\section{INTRODUCTION}

Ellis van Creveld syndrome (EVC) is a rare genetic disorder with disproportionate dwarfism characterized by postaxial polydactyly, several skeletal, oral mucosal and dental anomalies, nail dysplasia and presence of congenital cardiac defects. The syndrome, also known as chondroectodermal dysplasia, is an autosomal recessive disorder with mutations of the EVC-1 and EVC-2 genes located on chromosome 4P16. ${ }^{1}$ The first full description of the syndrome was given by Richard Ellis and Simon Van Creveld in $1940 .{ }^{2}$ A large number of cases have been reported in the Amish Community of Lancaster, Pennsylvania, USA, by McKuisk in 1964. ${ }^{3}$ Here, we report a case of EVC who presented for the first time at 30 years of age .

\section{Case Report :}

30 year old male presented with progressive shortness of breath since adolescence (Class- II- III NYHA) for which he was evaluated at a primary care centre. There was no history of consanguity in parents. There was no detail documents available, however he was evaluated in a primary health centre and was prescribed with diuretics without detailed cardiac evaluation and remained on the same treatment for several years. This admission, he presented with history of progressive breathlessness for 15 days with associated orthopnea and paroxysmal nocturnal dyspnea for the same duration. He also developed progressive abdominal swelling and swelling of both limbs for 10 days duration along with increased bluish discoloration of his face and hands and feet.

On examination, he had a short stature of $130 \mathrm{~cm}$ and weight of $36 \mathrm{~kg}$. His examination revealed six digits in each hand ( $X$-rays as shown in Fig. 1 and 2). The distal and middle segments of hands and feet were short. Clinodactyly of fifth fingers were present along with dystrophic and hypoplastic nails. (Fig 2). There was widened space between hallux and the rest of the toes as well as genu valgum being present (Fig 3) . His oromaxillary examination revealed deficient muco buccal fold with ankyloglossia and dental malocclusion defects (Fig4) The patient did his schooling till 10 th standard but had normal psychomotor and cognitive development. . He was cyanosed (oxygen saturation $\sim 80 \%$ ) at room air. The jugular

\footnotetext{
* Corresponding author

Anish Hirachan

Department of Cardiology

NAMS, Kathmandu, Nepal
} 
venous pulse (JVP) was elevated with prominent ' $a$ ' wave. The patient had long and narrow appearing thorax with a precordial bulge. There was cardiomegaly, with apex beat at left 6 th intercostal space, $4 \mathrm{~cm}$ lateral to the mid- clavicular line. Grade III/III left parasternal heave was present. The first heart sound was loud; the second sound was widely split and fixed. The pulmonary component was loud. There was a grade $3 / 6$ pansystolic murmur with inspiratory accentuation audible at left lower sternal border. Chest X-ray revealed cardiomegaly with right atrial enlargement while his ECG revealed normal $P$ wave axis and right axis deviation, $p^{\prime}$ pulmonale with RVH . His echocardiographic examination revealed situs solitus, enlarged right ventricle and a common atrial chamber without any interatrial septum (Fig. 5) . The right and left components of the common AV valves were at the same place with evidence of regurgitation through both the components of the valve. There was evidence of pulmonary arterial hypertension (PAH) in the form of right ventriculo- atrial gradient of $89 \mathrm{~mm} \mathrm{Hg}$. A diagnosis of common atrium anomaly with severe $\mathrm{PAH}$ was made.

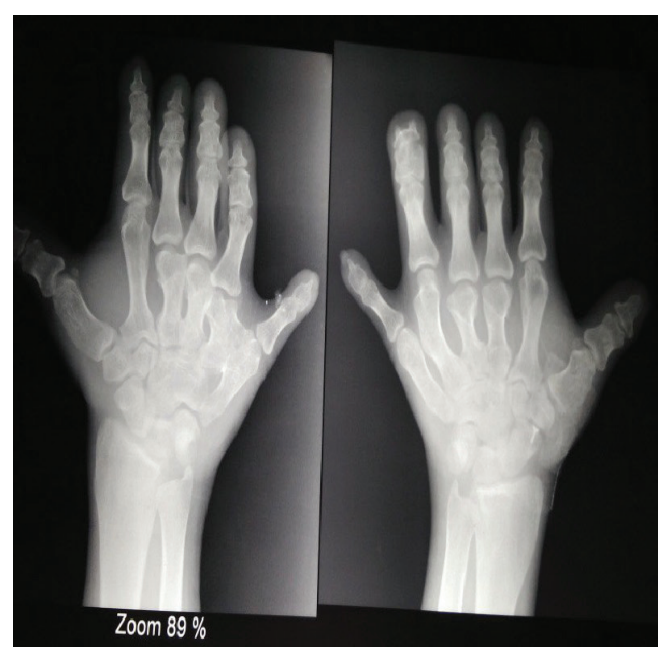

Fig : 1 Polydactyly

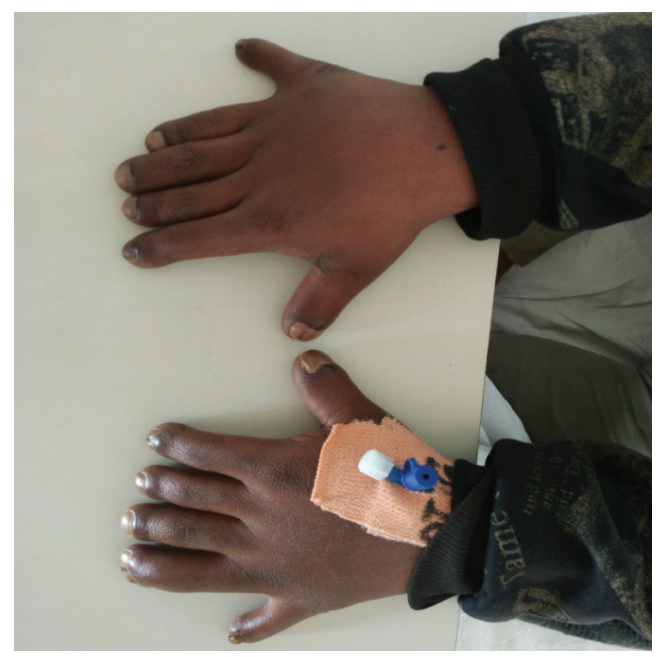

Fig 2 : Polydactyly with nail dystrophy

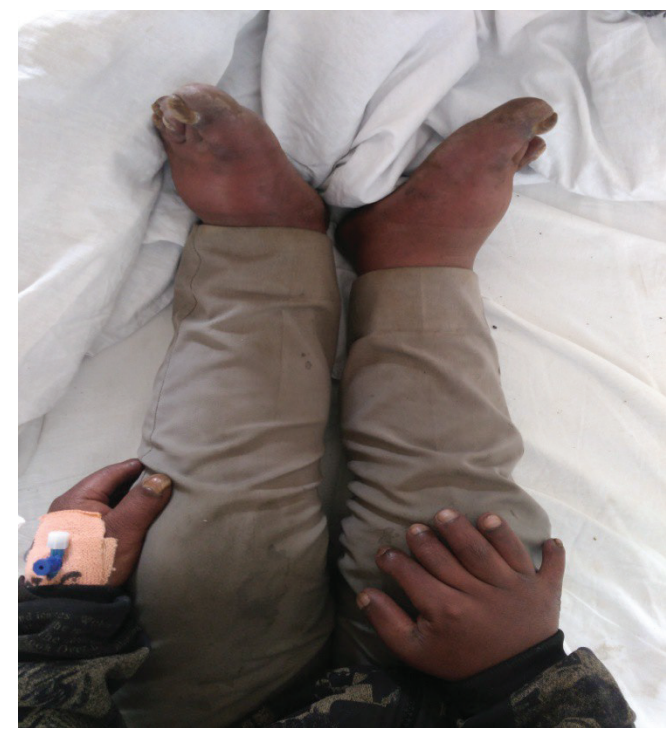

Fig 3 : Limb deformity with genu valgum, talipus equinovarus

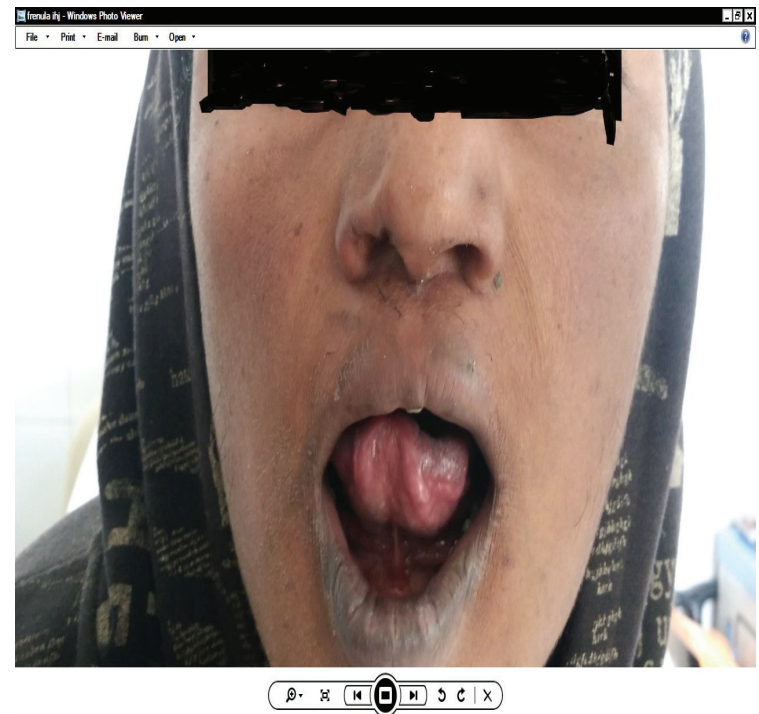

Fig 4 : Oromaxillary defect with dental malocclusion, ankyloglossia

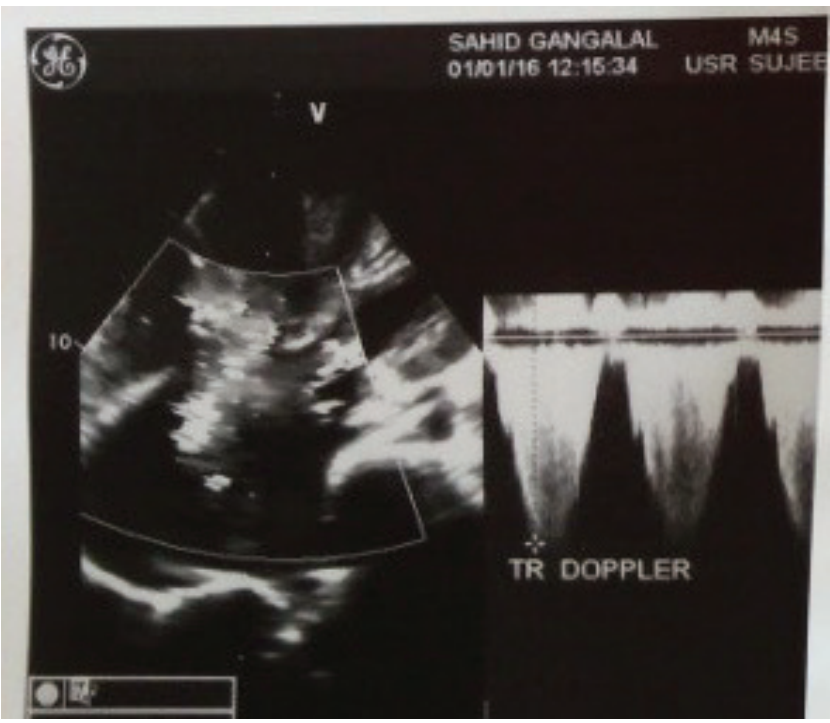

Fig 5 : Common atrium defect with TR jet and PAH 


\section{Discussion:}

Ellis van Creveld syndrome (EVC) otherwise known as chondroectodermal dysplasia has autosomal recessive inheritance . It is a syndrome found in Amish population of Pennsylvania in USA, affecting male and female equally. ${ }^{4}$ Familial history is significant with parental consanguinity or with affected siblings or family members. Polydactyly is a constant finding in the hands, and is usually bilateral, postaxial and on the ulnar side. Polydactyly of the feet is present in only $10 \%$ of the patients ..$^{5}$ Recently, the syndrome has been included in a new class of human genetic disorders called 'Ciliopathies', where the underlying defect may be dysfunctional molecular mechanism in the primary cilia of cells. ${ }^{6}$ The phenotype of the syndrome is variable and can affect multiple organs.

Other features include genu valga, curvature of the humerus, talipes equinovarus pectus carinatum with long narrow chest . Congenital heart malformations are described in a $50 \sim 60 \%$ of patients. The anomalies include defects of the mitral and tricuspid valves, patent ductus arteriosus, ventricular septal defect, atrial septal defect and hypoplastic left heart syndrome which are the principal causes of decreased life expectancy in these patients. ${ }^{7,8}$ The disease has characteristic oral manifestations that help early diagnosis at birth or during early childhood. The most common among them include fusion of the upper lip to the gingival margin resulting in the absence of mucobuccal fold, broad maxillary labial frenum described as partial harelip, multiple small accessory frenula, ankyloglossia, malocclusion etc. ${ }^{9}$

In the present index case, he had short stature, genu valgum , cynaosis, postaxial polydactyly of hands, hypoplastic and deformed nails and toes, and multiple frenula of lower lip were present. The patient had congenital heart disease in form of common atrium with severe mitral and tricuspid regurgitation and severe pulmonary hypertension. The syndrome is characterized by high mortality in infancy and early life because of severe restriction imposed by short ribs

syndrome with unusual association of essential infantile esotropia. Oman J Ophthalmo. 2010; 3(1):23 e 25.

2. Ellis R WB, Van Creveld S. Syndrome characterized by ectodermal dysplasia, polydactyly, chondro-dysplasia and congenital morbuscordis: resultof three cases. ArchDisChild.1940;15:65e84

3. Baujat G, Le Merrer M. Ellisevan Creveld syndrome: review. Orphanet J Rare Dis. 2007;2:27

4. Ghanekar J, Sangrampurkar S, Hulinaykar R, Ahmer T. and narrow thorax.${ }^{10}$ Presence of congenital heart diseases like common atrium, AV canal defect and VSD also contribute to early morality.

Rudnik -Schoneborn et al described about 2 patients with EVC syndrome who were 18 and 30 years old respectively.$^{11}$ Verbeek et al summarized growth data of 101 patients with EVC syndrome, including 10 patients above 20 years of age ${ }^{12}$ We experienced this first case report from Nepal documented in literature of an adult with Ellis van Creveld syndrome presenting as complex congenital heart disease with Common atrium anomaly . One third of these patients die at the early age or at infancy from cardiorespiratory problems and those who survive require multidisciplinary approach for treatment i.e. orthopedic correction of genu valgum, amputation of extra digits, surgical repair of cardiac malformations and dental intervention for high caries risk individuals.$^{13}$

\section{Conclusion :}

A case has been reported here with classic features of Ellis van Creveld syndrome who presented late in life with little complications developed until presentation to the hospital. It is a rare congenital disorder, with a high mortality in early life, $1 / 3$ of these patients die in infancy from cardiac and respiratory problems and those who survive require multidisciplinary approach for treatment

\section{Acknowledgement:}

I would like to acknowledge the patient and their relatives who had given consent and were cooperative enough to conduct this study. I must acknowledge the cardiology ward, the family of department of cardiology and hospital authority; without their help this study would not have been possible .

\section{References :}

1. Das D, Das G, Mahapatra JKS, et al. Ellise van Creveld Ellis van Creveld syndrome. J Assoc Physicians India 2009; $57: 532$-4.

5. Al-Khenaizan S, Al Sannaa N, Teebi AS. What syndrome is this? Chondroectodermal dysplasia- The Ellis van Credveld syndrome. Pediatr Dermatol. 2001;18(1):68-70

6. Badano JL, Mitsuma N, Beales PL, et al. The ciliopathies: an emerging class of human genetic disorders. Annu Rev Genomics Hum Genet. 2006;7:125e148

7. Gopal G, Belavadi GB. Case report of a child with 
Ellis-Van creveld syndrome. Int J Pharm Biomed Res. 2014;5:14e17.

8. Cesur Y, Yuca SA, U* ner A, Yuca K, Arslan D. Ellis-Van Creveld syndrome. Eur J Gen Med. 2008;5:187e190

9. Cahuana A, Palma C, Gonz_ales W, Ge_an E. Oral manifestations in Ellis-van creveld syndrome. Rep Five Cases Pediatr Dent. 2004;26:277e282

10. Goldmuntz E, Lin AE. Genetics of congenital heart defects. Allen HD, Driscoll DJ, Shaddy RE, Feltes TF, eds. Moss and Adams' Heart Disease in Infants, Children and Adolescents. 7th ed. Lippincott, Williams and Wilkins; 2008:563.

11. Rudnik-Schoneborn S, Zerres K, Graul Neumann L, et al. Two adult patients with Ellisevan Crevald syndrome extending the clinical spectrum. Mol Syndromol. 2011 sep;1(6):301e306. EPub 2011 Sep 14

12. Verbeek S, Eilers PH, Lawrence K, Hennekam RC, Versteegh FG. Growth charts for children with Ellis-van Creveld syndrome. European journal of pediatrics. 2011 Feb 1;170(2):207-11.

13. Kurian K, Shanmugam S, Harshuardhas $T$. Chondroectodermal dysplasia (Ellis van Creveld syndrome): A report of three cases with review of literature. Indian J Dent Res 2007;18(1):31-4 